\title{
Simulators for intimate examination training in the developing world
}

Bohaira Geyoushi, MRCOG, MFFP, Research Fellow, 'Opportunities and Choices' Programme, University of Southampton, Southampton, UK; Kalpana Apte, BAMS, DHM, Director of Training, Family Planning Association of India, Mumbai, India; R William Stones, MD, FRCOG, Senior Lecturer, 'Opportunities and Choices' Programme, University of Southampton, Southampton, UK

Correspondence: Dr R W Stones, Level F (815), Princess Anne Hospital, Southampton SO16 5YA, UK. Tel: +44 (0) 2380796033. Fax: +44 (0) 2380 786933.E-mail: r.w.stones@soton.ac.uk

(Accepted $18^{\text {th }}$ October 2002)

Journal of Family Planning and Reproductive Health Care 2003: 29(1): 34-35

\begin{abstract}
Context. Family planning clinic in urban India.

Objective. To assess the usefulness of a pelvic simulator for intimate examination and intrauterine device insertion training, and for enhancing reproductive education for women.

Design. Observational study using evaluation forms completed by staff, and focus group interviews with women and girls participating in sexual health education. Content analysis of interview material.

Results. Staff being trained in intimate examination found the simulator to be useful in increasing their level of skill. Participants in sexual health education reported an improved range and depth of knowledge following demonstrations with the simulator.

Conclusion. Where working and training conditions are crowded and lacking in privacy, inappropriate examination practices are likely to be propagated. Training for intimate examinations can be enhanced by the use of pelvic simulators.
\end{abstract}

\section{Introduction}

Examination of the female genitalia is the most intimate and potentially embarrassing element of a clinical consultation. Women in both developed and developing countries often find the experience of gynaecological examination offputting and unpleasant and this has important implications for the utilisation of gynaecological and family planning services. Apprehension and anticipation may be worse than the actual experience: Norwegian women reported that the experience was 'not so bad after all'. ${ }^{1}$ The Royal College of Obstetricians and Gynaecologists published standards for intimate examination in 1997 which emphasised the provision of adequate privacy, the presence of a chaperone, the maintenance of verbal communication for reassurance, and allowing women to dress and be seated in the consulting room for any discussion of the results of the examination or future proposed treatment. Further aspects, especially relating to training, were highlighted in the recently updated document. ${ }^{2}$

This aspect of quality of care has received little attention in developing countries, with no published assessments of the training needs of medical and paramedical staff in intimate examination. In the present study we evaluated the use of a pelvic simulator for training of medical and nonmedical staff in a family planning setting, and for enhancing reproductive education for women.

\section{Methods}

A commercially available but expensive pelvic simulator (NASCO, Fort Atkinson, WI, USA) was provided to a trainer at a Mumbai clinic of the Family Planning Association of India for the one-to-one training of 20 staff in pelvic examination and intrauterine device (IUD) insertion. Interviews were then conducted with the trainer and a trainee. Feedback was received through information collected from an evaluation form completed by the trainer and six trainees.

The pelvic model was also used as a teaching aid during sexual health educational lectures arranged for adult women and adolescent girls in the local community, who were not specifically users of the family planning service. Two focus group interview sessions were carried out with those who had attended a lecture. The first group consisted of 18 women between the ages of 16 and 48 years and the second group consisted of 32 adolescent girls aged between 13 and 19 years. Notes of the discussions were taken, and comments transcribed and analysed for content.

\section{Results}

The trainer and all six trainees agreed that the model was very useful for their training needs in IUD insertions and vaginal examination. All trainees felt that the model was easy to use and was sufficiently lifelike. The overall level of satisfaction was very high and the trainees did not feel that the pelvic model needed any improvements or modifications although they felt they needed a longer period of training than was generally available. Comments were that the pelvic model simulator helped them to gain more confidence and skill prior to inserting an IUD into an actual patient, avoiding awkwardness and fumbling.

Regarding the model's use in a sexual health educational context, content from the two focus groups showed a similar level of knowledge and needs among the adult women and adolescent girls. Recurring themes were:

\section{Initial embarrassment}

"We giggled, we were embarrassed, we did not want to touch it initially but due to encouragement from the doctor we all touched and felt it." (Adolescent girls) "We felt embarrassed to look at it initially ...." (Adult women)

\section{The female anatomy}

Both groups had limited knowledge of the separate urethral and vaginal openings. "I now know bleeding is not harmful and doesn't come from the urinary opening." (Adolescent) "We understood the differences between uterus and vagina, and urethral opening." (Adult women) 


\section{Understanding and removing fears about pregnancy and labour}

"I used to be petrified about childbirth and never understood how a big child can pass through such a small opening. Knowing about labour, I feel a little calm and I am happy that I understand things better." (An 18-year-old girl about to get married) "Now I know ... how the uterus can grow in my tummy and why I urinated so frequently when I was pregnant."(Adult woman) "I used to be petrified about childbirth...I now understand things better." (Engaged girl) 4. Menstruation

"I understand where menstrual blood comes from...I will be able to tell my daughter that menstrual pain is not abnormal. It is part of growing up." (Adult woman)

\section{Contraception}

There was a lack of prior knowledge about the IUD, which was easily dispelled by demonstration using the simulator. "I now know where the copper $T$ is placed, before we thought that it was in the vagina." (Adult woman)

Other content related to understanding of personal hygiene, vaginal discharge, the effects of the menopause and the potential usefulness of seeing a model of the male anatomy was also discussed.

\section{Discussion}

In developing countries, medical students' learning of pelvic examination is constrained by the limited availability of informative literature, audio-visual material and simulators. Working and training conditions are often crowded and lacking in privacy so that inappropriate practices with regard to pelvic examination are likely to be propagated. However, as a simple and non-costly clinical skill there is no fundamental reason why vaginal examination should not be properly learned and practised in poor countries.

While some guidance for nurses is available, ${ }^{3}$ training materials are usually designed for use by doctors. In Western countries innovative approaches have included the use of 'assistants', volunteers who are prepared to allow students to undertake intimate examinations, providing guidance and feedback. ${ }^{4}$ This concept may not be culturally acceptable in many developing countries and does not provide adequate simulation of IUD insertion. We believe the wider use of pelvic simulators would enhance the training in, and quality of, family planning services.

Sexual health education can be undertaken very effectively using line drawings and does not require expensive or complex tools such as a simulator. ${ }^{5}$ However, our study suggests that such a device can also be of great interest to clients. Local manufacture and distribution of low-cost pelvic simulators for training needs to be considered with support from funding agencies active in reproductive health.

\section{Conclusions}

Where working and training conditions are crowded and lacking in privacy, inappropriate examination practices are likely to be propagated. Training for intimate examinations can be enhanced by the use of pelvic simulators. Further research is needed to quantify the extent of non-use of services resulting from clients' fears of ineptly performed intimate examinations, compared to other barriers to access.

\section{Statements on funding and competing interests}

Funding. This study was funded by the UK Government Department for International Development through the 'Opportunities and Choices' knowledge programme in reproductive health based at the University of Southampton, Southampton, UK.

Competing interests. None identified.

\section{References}

1 Larsen M, Oldeide C, Malterud K. "Not so bad after all ...": women's experiences of pelvic examinations. Fam Pract 1997; 14: 148-152.

2 Royal College of Obstetricians and Gynaecologists (RCOG) Working Party Report. Gynaecological examinations: guidelines for specialist practice. London: RCOG Press, 2002.

3 Addison R, Lavender R. Practical procedures for nurses. Vaginal examination - 1. Nurs Times 1999; 95(47)(Insert).

4 Abraham S. Gynaecological examination: a teaching package integrating assessment with learning. Med Educ 1998; 32: 76-81.

5 Lupiwa S, Suve N, Horton K, et al. Knowledge about sexually transmitted diseases in rural and periurban communities of the Asaro valley of Eastern Highlands province: the health education component of a STD study. P N G Med J 1996; 39: 243-247.

\section{Provider resistance to advance provision of oral contraceptives in Africa}

John Stanback, PhD, Senior Associate; Barbara Janowitz, PhD, Director, Health Services Research, Family Health International, Research Triangle Park, NC, USA

Correspondence: John Stanback, Family Health International, PO Box 13950, Research Triangle Park, NC 27709, USA. Tel: +1 919 405 1473. Fax: +1919544 7261.E-mail: jstanback@fhi.org

(Accepted $4^{\text {th }}$ August 2002)

Journal of Family Planning and Reproductive Health Care 2003: 29(1): 35-36

\begin{abstract}
Context. In Africa, many new family planning clients are not menstruating at the time they present for services. Where pregnancy tests are unavailable, clients are often denied their method of choice and sent home to await menses. For pill clients, one obvious solution is 'advance provision' of oral contraceptives for later use. However, this practice is rare in Africa.
\end{abstract}

Objective. To assess the level of provider resistance to advance provision of oral contraceptives.

Design. We added questions about advance provision of pills to five provider surveys in three African countries. We also used simulated clients in Ghana to assess provider resistance to the practice.

Results. In Kenya, only $16 \%$ of providers thought it safe to give women oral contraceptives to be started at a later date. 